\title{
LOS EUROCÓDIGOS ESTRUCTURALES
}

\author{
(STRUCTURAL EUROCODES)
}

Javier Serra Ma-Tomé, Arquitecto. Asesor de la Fundación Cultural COAM

ESPAÑA

Fecha de recepción: 28-X-96

\section{RESUMEN}

El propósito de este artículo es dar una idea general de un nuevo tipo de documentos técnicos de carácter europeo que están viendo la luz en la última década de este siglo en el ámbito de la construcción. El artículo trata su origen, programa inicial, desarrollo y evolución hasta su actual desarrollo dentro del Comité Europeo de Normalización. Se explicará cual es su porvenir y los problemas que están surgiendo en su adopción como normas europeas, particularmente en España donde los eurocódigos aparecen en competencia con normas técnicas de carácter reglamentario.

\section{SUMMARY}

This article aims to give a general idea on a new kind of European technical documents which are been issued in the last decade of this century in the construction field. The article goes from the origin, initial program, further developments and the last evolution towards the European Standardization Committee CEN. It also deals with the future of this brand new European standards and with the problems arisen when they are been adopted as standards with an special mention to Spain where they have to meet the national regulations in the same field.

\section{Preámbulo}

No se pretende, por tanto, en las líneas que siguen a continuación dar una información exhaustiva ni detallada sobre los mismos, que, en todo caso, puede obtenerse bien en AENOR, en el correspondiente comité técnico (AEN/CTN 140) como en las propias administraciones españolas y europeas encargadas de su seguimiento.(respectivamente el Ministerio de Fomento y la DG IIID3 de la Comisión Europea)

La mayoría del contenido de este artículo ha sido tomado de diversos informes y documentos de la Comisión Europea y del Comité Europeo de Normalización que están disponibles en la Asociación Española de Normalización y Certificación AENOR y en los servicios competentes del Ministerio de Fomento.

\section{Origen y objetivo de los Eurocódigos}

En 1975 la Comisión de las Comunidades Europeas decidió abordar un programa sobre la industria de la construcción que, basándose en el artículo 100 del Tratado, tenía como objetivo la eliminación de las barreras técnicas mediante la armonización de las especificaciones técnicas de los Estados miembros.

Así nacieron los Eurocódigos estructurales (en lo sucesivo citados como Eurocódigos o EC), que fueron definidos como las reglas unificadas para el proyecto de diferentes estructuras construidas de diferentes materiales. No solamente consistirían en la armonización de los métodos de cálculo sino que introducirían nuevos métodos de proyecto basados en los estados límites, determinados mediante métodos probabilísticos. 
Fue también en esos momentos cuando, por iniciativa de la Comisión de las Comunidades Europeas, fue preparado en paralelo el primer borrador de la directiva sobre productos de construcción (DPC), legislación comunitaria con la que los eurocódigos acabarían teniendo cierta relación.

Se pretendió que los Eurocódigos fuesen empleados de forma común en todos los Estados miembros de la Unión Europea y que contuviesen disposiciones técnicas y requisitos (conocidos como reglas de proyecto o de diseño) con el objetivo de asegurar una seguridad adecuada de las estructuras.

De esta manera, los Eurocódigos, no sólo promoverían el funcionamiento del mercado común mediante la eliminación de las barreras técnicas derivadas de las diversas reglas técnicas divergentes, sino que facilitarían el intercambio de los servicios de la construcción en el ámbito europeo, así como la exportación de tales servicios a terceros países.

\section{Bases técnicas de los ECs}

Los EC están basados en conceptos de proyecto modernos y unificados, los conceptos de los estados límite. Un estado límite se define como una situación en la que un elemento estructural llega al punto de no satisfacer unos requisitos dados. Los estados límites pueden dividirse en estados límites de servicio y estados límites últimos.

En 1979, los Estados miembros de la entonces Comunidad Económica Europea reconocieron que el trabajo de los Eurocódigos era de gran importancia para ésta, y, por iniciativa de la Comisión Europea, comenzaron los estudios de base y trabajos de redacción con el objetivo de codificar las reglas modernas y avanzadas para el cálculo y el proyecto de las estructuras de la construcción.

Los estudios para la redacción de los Eurocódigos se han basado en los denominados Códigos modelo y en las recomendaciones de las organizaciones técnico científicas internacionales siguientes:

\section{CEB: Comité Euro-Internacional del Hormigón}

CECM: Convención Europea de las Estructuras de Acero

CIB: Consejo Internacional para la Investigación, Estudios y Documentación de la Edificación

FIP: Federación Internacional del Hormigón Pretensado

ISSMFE : Sociedad Internacional de Mecánica de Suelos y de Ingeniería Geotécnica

IABSE: Asociación Internacional de Ingeniería de Puentes y Estructuras

(c) Consejo Superior de Investigaciones Científicas

Licencia Creative Commons 3.0 España (by-nc)
RILEM: Asociación Internacional de Laboratorios de ensayos e investigación de materiales de construcción

JCSS: Comité Conjunto sobre la Seguridad de las Estructuras

CICIND: Comité Internacional de Chimeneas Industriales

CIGR: Comité Internacional de Ingeniería Rural

También han sido tenidos en cuenta los documentos y normas ISO correspondientes que han estado disponibles.

\section{Programa y estatus inicial}

Se estableció un programa inicial de 9 Eurocódigos, que, en gran medida, se ha mantenido hasta ahora. Debido a la implicación de los Eurocódigos con la reglamentación nacional o regional de la construcción se pensó, al comienzo de su desarrollo por parte de algunos expertos, que estos documentos debieran aprobarse a través de una Directiva del Consejo.

Sin embargo, a causa de su gran contenido técnico, su particular forma de elaboración, así como las diferencias de estatus (legal o voluntario) que tales códigos tienen en los diversos Estados miembros, hicieron inadecuada su aprobación a través de una directiva, quedando indefinida la forma jurídica que finalmente adoptarían.

El programa inicial, preparado por un Comité de Dirección, formado por representantes gubernamentales y de las más importantes organizaciones técnicas internacionales, estaba compuesto de los 9 Eurocódigos siguientes:

EC1. Bases del proyecto (reglas comunes unificadas de todos los ECs)

EC2. Reglas de proyecto para las estructuras de hormigón EC3. Reglas de proyecto para las estructuras de acero EC4. Reglas de proyecto para las estructuras mixtas de hormigón y acero

EC5. Reglas de proyecto para las estructuras de madera EC6. Reglas de proyecto para las estructuras de fábrica EC7. Reglas de proyecto para las cimentaciones

EC8. Reglas de proyecto para las estructuras en zonas sísmicas

EC. Acciones Reglas de proyecto para las acciones en estructuras

\section{Relación de los Eurocódigos con la DPC}

Inicialmente, la intención de los Eurocódigos fue crear un medio o lenguaje técnico que armonizase las dispersas reglas existentes en el ámbito de la Comunidad europea. 


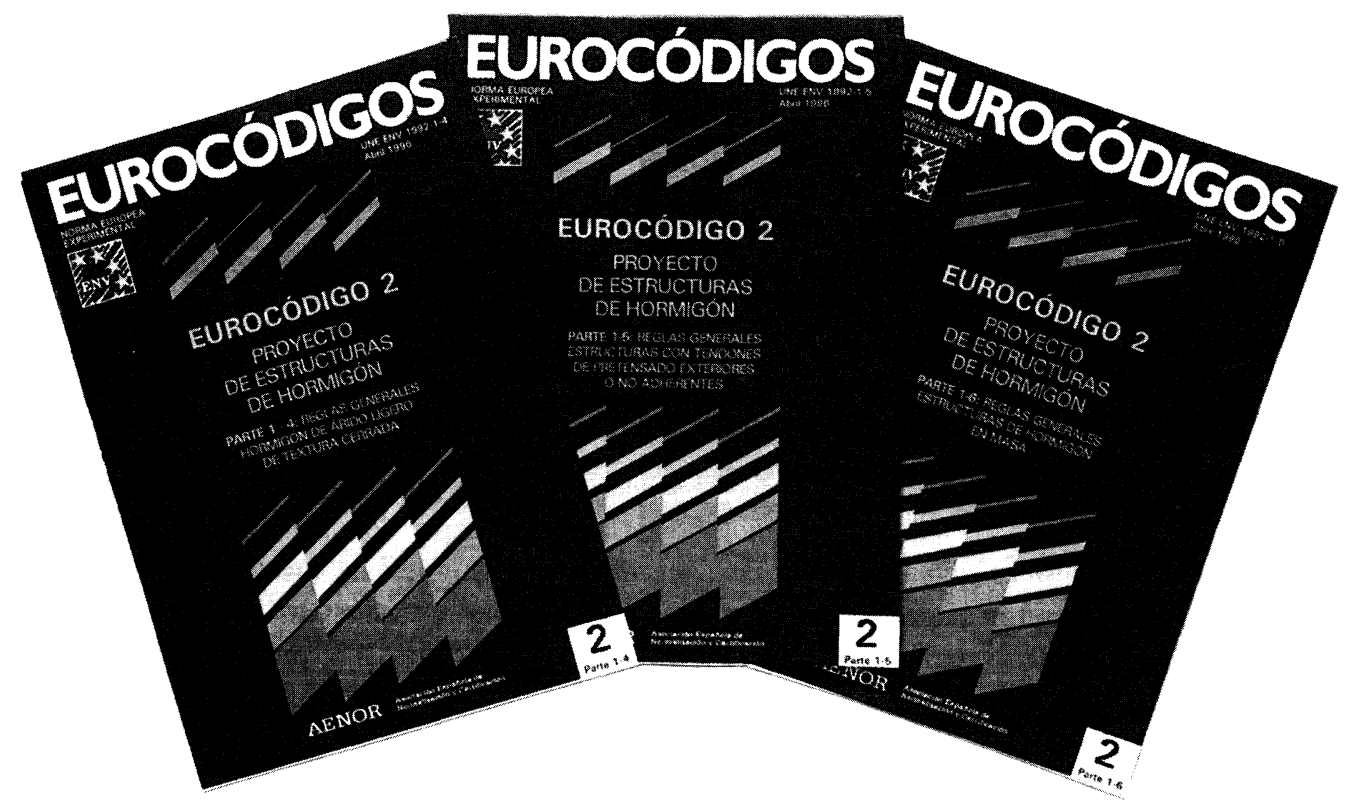

Como se ha dicho, no se sabía por entonces qué forma jurídica adoptarían finalmente.

En 1988, la directiva sobre productos de construcción DPC fue aprobada por el Consejo y desde entonces es aplicable a todos los productos que se incorporan de forma permanente a las obras de construcción, que incluyen la edificación y las obras de ingeniería civil. Esta disposición comunitaria, como otras del denominado nuevo enfoque, requieren para su aplicación efectiva el establecimiento de normas europeas a elaborar por la industria europea en el Comité Europeo de Normalización CEN.

La directiva ha establecido los requisitos esenciales que afectan a las obras de construcción y que se desarrollan en los llamados Documentos Interpretativos. El primero de estos requisitos es el de "Resistencia mecánica y estabilidad". En consecuencia, los Eurocódigos pueden considerarse como normas fundamentales que tienen una relación directa con la DPC.

En este contexto, los Eurocódigos podrán servir como un medio para demostrar el cumplimiento de una obra de edificación e ingeniería civil, con el requisito esencial número 1 como base de los pliegos de condiciones para la ejecución de contratos públicos o privados de este tipo de obras y como marco para la redacción de normas europeas (y de guías de los documentos de idoneidad europeos -DITE-) de ciertos productos de construcción relacionados con estas estructuras.

Por lo tanto, se considera que los Eurocódigos han de servir para promover el funcionamiento del mercado interior a través de la eliminación de obstáculos técnicos que se derivan de las diferentes normativas de proyecto y cálculo, para aumentar la eficacia de la industria europea de la construcción y de las industrias subsidiarias, así como para reforżar la posición competitiva de esta industria fuera de la Comunidad europea y del Espacio Económico Europeo, mediante el ofrecimiento de conceptos avanzados de proyecto y cálculo, junto con tecnologías avanzadas en este sector.

\section{Transferencia de los Eurocódigos al Comité Europeo de Normalización}

Hacia 1990, los Servicios responsables de la Construcción en la Comisión Europea, después de unos dos años de discusiones, y en línea con las Conclusiones del Consejo de 1984 sobre la política europea de normalización, estudiaron, conjuntamente con los Estados miembros y otras organizaciones interesadas, la forma y manera en que los trabajos de los Eurocódigos, gestionados hasta ese momento directamente desde la propia Comisión, se incorporasen a las tareas de normalización desarrolladas en Europa y, por lo tanto, se transfiriesen al CEN.

Así ocurrió, finalmente, por medio de la firma de un convenio entre la Comisión y el CEN para transferir a esta organización todo el trabajo de los Eurocódigos, estableciendo un mandato marco para un programa de normalización europea y varios mandatos específicos provisionales para cada uno de los Eurocódigos.

\section{Los Eurocódigos como normas europeas experimen- tales}

En definitiva, y como consecuencia de la transferencia al CEN, los Eurocódigos son normas europeas (EN), que inicialmente son aprobadas con carácter experimental 
(ENV), que tienen su reflejo o transposición en sus equivalentes normas nacionales (en España UNE-EN), y que son elaboradas bajo encargo de la Comisión Europea por el CEN, como resultado de un acuerdo marco entre ambas instituciones.

Comprenden las reglas de proyecto y cálculo de las distintas clases de estructuras empleadas en la construcción y tienen como objeto establecer un lenguaje técnico armonizado en este campo, para su posible empleo en los ámbitos de las directivas europeas de contratos públicos y de productos de construcción.

Debido al acuerdo citado, tienen un carácter diferente de las demás EN en cuanto a que tratan aspectos que, en muchos Estados de la $\mathrm{CE}$, son materia reglamentaria.

\section{Situación actual del programa}

El programa de Eurocódigos prevé ser desarrollado en numerosas normas, algunas de las cuales ya están aprobadas, con el carácter de normas europeas experimentales ENV, como se dijo anteriormente.

En España todas ellas tienen en común la designación UNE EN 199X-Y-Z, siendo " $X$ " el número asignado inicialmente al Eurocódigo correspondiente, e " $Y$ " $y$ " $Z$ " las diferentes partes previstas.

\section{El programa comprende las siguientes normas:}

Reglas generales para todas las estructuras, incluidas las acciones (EC-1),

Reglas para las estructuras de hormigón (EC-2),

Reglas para las estructuras de acero (EC-3),

Reglas para las estructuras mixtas (EC-4),

Reglas para las estructuras de madera (EC-5),

Reglas para las estructuras de fábrica (EC-6),

Reglas para las estructuras geotécnicas (EC-7),

Reglas para estructuras simorresistentes (EC-8) y

Reglas para las estructuras de aluminio (EC-9).

Cada Eurocódigo, a su vez tiene diversas partes relativas a la clase de obras en donde se aplican: edificios, puentes, etc. El programa actual prevé más de 50 partes, de las cuales están disponibles alrededor de unas 20 .

En el apéndice que se acompaña se incluye un cuadro que ha sido facilitado por AENOR y que refleja la situación, a

(c) Consejo Superior de Investigaciones Científicas Licencia Creative Commons 3.0 España (by-nc) mediados de 1996, de las diversas partes del programa, situación que, evidentemente, va cambiando día a día.

\section{Los Eurocódigos y las normativas nacionales. Posi- ción española}

Como ya se ha indicado antes, en cada país de la Unión Europea la situación jurídica de los documentos concurrentes con los Eurocódigos es muy diversa.

Ello plantea diversas situaciones, en función de cada país, al tener que aplicarse las Reglas del CEN por lo que se refiere a la obligación de sus miembros de tener que adoptar las normas europeas en un determinado plazo de tiempo, una vez aprobadas, a la vez que retirar las normas nacionales existentes que entren en concurrencia o colisión con las normas-Eurocódigos.

Se puede afirmar que en España las normas concurrentes con ellos no son normas nacionales, en el sentido que se entiende en la normalización europea (que serían las normas UNE), sino que, obien son normas reglamentarias, de obligado cumplimiento como las instrucciones o las normas básicas de la edificación NBE, o bien no encuentran competencia porque, simplemente, no existen.

Por tanto, en España, la obligación de transponer todas y cada una de las partes de los Eurocódigos corresponde a AENOR, la Asociación Española de Normalización y Certificación, que es el miembro correspondiente del Comité Europeo de Normalización CEN.

La aparición de un Eurocódigo que entre en concurrencia con una reglamentación técnica española no supone, en principio, más que la existencia de una opción alternativa a ésta, en la medida en que esta alternativa esté permitida por la propia reglamentación. Esta libertad del proyectista para evitar la norma reglamentaria suele existir en muchas de ellas por lo que teóricamente no debiera haber impedimiento para su uso.

La realidad es que la experiencia del empleo de algunas de las partes de Eurocódigos ya aprobados desde 1992 y 1993 es escasa o no es conocida y los ensayos que se han hecho de su uso se circunscriben a los ámbitos académicos o universitarios. Por otro, lado esta carencia de experiencia es análoga en los demás Estados miembros de la Unión europea.

\section{Los "box values" y los documentos nacionales de aplicación}

Otra particularidad de los Eurocódigos es la existencia de unos valores que sirven para establecer el nivel de seguridad de las estructuras. Son los llamados valores recuadrados ("box values") que aparecen en determinados apartados de 
ellos y que significan que el valor dado en tal recuadro podrá ser variado en cada país en la forma que se determine, de forma que el nivel de seguridad de las estructuras permanezca como una competencia de cada Estado miembro. De otra forma se habría alcanzado una armonización o igualación de estos niveles, cosa que por el momento no parece pretenderse

La existencia de estos valores recuadrados y otras particularidades, como el hecho de que no estén disponibles a la vez todas las partes de todos los Eurocódigos, ha hecho necesario recurrir a la mención de los denominados documentos nacionales de aplicación o DNA. Se pretende que estos DNA no sean otra cosa que un documento de acompañamiento del Eurocódigo donde se recojan los valores recuadrados o "box values" adoptados por cada país y otros datos complementarios que permitan una aplicación efectiva de ellos. Parece oportuno que tal adopción sea hecha, no por el organismo nacional de normalización, sino por las autoridades competentes en la materia.

\section{Situación actual y futura}

A mediados de 1996 la evolución de los Eurocódigos está condicionada por diversos interrogantes y cuestiones pendientes de resolver como las siguientes:

¿Deben aplicarse estrictamente las Reglas del CEN a los Eurocódigos o deben exceptuarse?

¿Deben coexistir los Eurocódigos con las reglas nacionales de proyecto y ejecución de las estructuras?

¿Cuál debe ser el calendario para la conversión y cuáles las prioridades?

¿Deben seguir existiendo los valores recuadrados?

¿Deben existir los documentos nacionales de aplicación en el futuro? ¿Y en caso de existir, deberían armonizarse?

¿Deben existir reglas simplificadas de los Eurocódigos?

Recientes consultas entre la Comisión y los Estados miembros permiten aclarar determinadas dudas al respecto de las cuestiones anteriores, habiéndose llegado a un cierto grado de entendimiento sobre los puntos que siguen:

-La escasa experiencia de su empleo es debida, quizás, al propio hecho de que al ser normas europeas experimentales no se confie suficientemente en su idoneidad, obien porque no se hayan desarrollado herramientas informáticas que faciliten su uso.

-Se ha considerado oportuno acortar el periodo de "experimentalidad" de las partes más recientes aprobadas, como ENV, con la idea de que se empleen como normas europeas EN.

-Se ha juzgado pertinente que esta conversión sea rápida, pero que a la vez permita la coexistencia con las viejas reglas nacionales que tengan el carácter de "normas", lo que debiera suponer una derogación de las reglas $\mathrm{CEN}$, que exigen la retirada de éstas.

-Parece imposible eliminar los valores recuadrados durante el proceso de conversión de ENV a EN.

-El número de valores recuadrados debe reducirse al mínimo estricto que represente el nivel de seguridad de las estructuras.

-Los valores recuadrados podrían ser convertidos en un sistema de clases de seguridad, o recopilados en algunos anexos, o bien pasados todos al EC1.

- Al final de la fase de conversión la necesidad de los DNA parece limitada, excepto para los puntos relacionados con los niveles de seguridad. 
$\mathrm{N}^{\circ}$ total previsto de documentos: $\ldots \ldots \ldots \ldots \ldots \ldots \ldots \ldots \ldots \ldots \ldots \ldots \ldots$

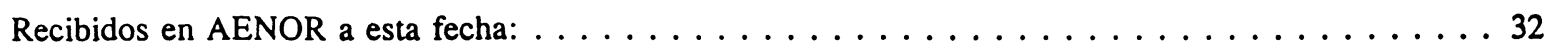

1.1.- Publicados como UNE Experimental: $\ldots \ldots \ldots \ldots \ldots \ldots \ldots \ldots \ldots \ldots \ldots \ldots \ldots \ldots$

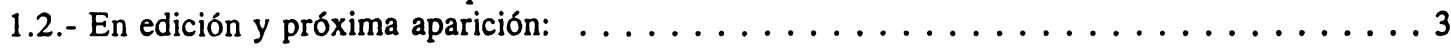

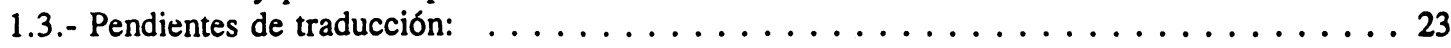

\begin{tabular}{|c|c|c|c|c|c|c|c|}
\hline \multicolumn{8}{|c|}{ EUROCODIGO 1: Bases de proyecto y acciones en estructuras } \\
\hline \multirow[b]{2}{*}{ Parte } & \multirow[b]{2}{*}{ Título abreviado } & \multirow[b]{2}{*}{ Disponibilidad } & \multicolumn{2}{|c|}{ AENOR } & \multicolumn{2}{|c|}{ Publicación } & \multirow{2}{*}{ Observaciones } \\
\hline & & & Recepción & Idioma & UNE & DNA & \\
\hline ENV 1991-1 & Bases de proyecto & 1994-09 & $1994-11-11$ & E-F-D & & & \\
\hline ENV 1991-2-1 & Densidades, peso propio y cargas impuestas & 1995-02 & $1995-02-10$ & E-F-D & & & \\
\hline ENV 1991-2-2 & Acciones en estructuras expuestas al fuego & 1995-02 & 1995-02-10 & E-F & & & \\
\hline ENV 1991-2-3 & Cargas de nieve & 1995-02 & $1995-02-10$ & E-F-D & & & \\
\hline ENV 1991-2-4 & Acciones del viento & 1995-05 & $1995-06-07$ & E-F-D & & & \\
\hline ENV 1991-2-5 & Acciones térmicas & $1996-05(*)$ & & & & & \\
\hline ENV 1991-2-X & Acciones accidentales & $1997-04(*)$ & & & & & \\
\hline ENV 1991-2-Y & Cargas y deformaciones durante la ejecución & $1997-10\left(^{*}\right)$ & & & & & \\
\hline ENV 1991-3 & Cargas de trafico en puentes & 1995-03 & $1995-03-21$ & E-F-D & & & \\
\hline ENV 1991-4 & Acciones en silos y tanques & $1995-05$ & $1995-06-07$ & E-F-D & & & \\
\hline ENV 1991-5 & Acciones inducidas por gruas y maquinaria & $1996-10\left(^{*}\right)$ & & & & & \\
\hline
\end{tabular}

EUROCODIGO 2: Proyecto de estructuras de hormigón

\begin{tabular}{|c|c|c|c|c|c|c|c|}
\hline \multirow[b]{2}{*}{ Parte } & \multirow{2}{*}{ Título abreviado } & \multirow[b]{2}{*}{ Disponiblidad } & \multicolumn{2}{|c|}{ AENOR } & \multicolumn{2}{|c|}{ Publicación } & \multirow[b]{2}{*}{ Obectractomes } \\
\hline & & & Recepción & Idioma & UNE & DNA & \\
\hline ENV 1992-1-1 & Reglas generales y reglas para edificación & 1991-12 & $1992-01-13$ & E-F-D & 1993-11 & & \\
\hline ENV 1992-1-2 & Proyecto de estructuras sometidas a fuego & 1995-11 & 1995-11-07 & E & & & \\
\hline ENV 1992-1-3 & Elementos prefabricados de hormigón & 1994-10 & $1994-11-11$ & E-F-D & 1995-12 & & \\
\hline ENV 1992-1-4 & Hormigón estructural con árido ligero & 1994-10 & $1994-11-11$ & E-F-D & 1996-04 & & \\
\hline ENV 1992-1-5 & Tendones de pretensado externos y sin adherencia & 1994-10 & $1994-11-11$ & E-F-D & 1996-04 & & \\
\hline ENV 1992-1-6 & Estructuras de hormigón en masa & 1994-10 & $1994-11-11$ & E-F-D & $1996-04$ & & \\
\hline ENV 1992-2 & Puentes de hormigón armado o pretensado & 1995-09 & 1996-09-19 & E & & & \\
\hline ENV 1992-3 & Cimentaciones de hormigón & $1996-03\left({ }^{*}\right)$ & & & & & \\
\hline ENV $1992-4$ & Estructuras de retención o contención de líquidos & $1996-10\left(^{*}\right)$ & & & & & \\
\hline
\end{tabular}

EUROCODIGO 3: Proyecto de estructuras de acero

\begin{tabular}{|c|c|c|c|c|c|c|c|}
\hline \multirow[b]{2}{*}{ Parte } & \multirow[b]{2}{*}{ Título abreviado } & \multirow[b]{2}{*}{ Disponibilidad } & \multicolumn{2}{|c|}{ AENOR } & \multicolumn{2}{|c|}{ Publicación } & \multirow[b]{2}{*}{ Observaciones } \\
\hline & & & Recepción & Idioma & UNE & DNA & \\
\hline ENV 1993-1-1 & Reglas generales y reglas para edificación & $1992-04$ & $1992-05-25$ & E-F-D & & & Impienta \\
\hline ENV 1993-1-1/A1 & Anexo $\mathrm{D}$ y $\mathrm{K}$ revisado & $1994-12$ & $1994-12-21$ & E-F & & & Imprenta \\
\hline ENV 1993-1-1/A2 & Anexos $\mathrm{G}, \mathrm{H} \mathrm{J}$ revisado, $\mathrm{N}$ y $\mathrm{Z}$ & $1996-02(* *)$ & & & & & \\
\hline ENV 1993-1-2 & Proyecto de estructuras sometidas a fuego & $1995-09$ & $1995-09-26$ & $\mathbf{E}$ & & & \\
\hline ENV 1993-1-3 & Chapas finas conformadas en frío & $1996-04$ & $1996-04-08$ & $\mathbf{E}$ & & & \\
\hline ENV 1993-1-4 & Uso del acero inoxidables & $1996-09$ & $1996-09-19$ & $\mathbf{E}$ & & & \\
\hline ENV 1993-2 & Puentes y estructuras de chapa & $1996-10(*)$ & & & & & \\
\hline ENV 1993-3 & Torres, mástiles y chimeneas & $1996-10(*)$ & & & & & \\
\hline ENV 1993-4 & Tanques, silos y conducciones & $1996-10(*)$ & & & & & \\
\hline ENV 1993-5 & Pilotaje & $1997-04(*)$ & & & & & \\
\hline ENV 1993-6 & Estructuras de gría & $1996-10(*)$ & & & & & \\
\hline
\end{tabular}


EUROCODIGO 4: Proyecto de estructuras mixtas de acero y hormigón

\begin{tabular}{|c|c|c|c|c|c|c|c|}
\hline \multirow[b]{2}{*}{ Parte } & \multirow[b]{2}{*}{ Título abreviado } & \multirow[b]{2}{*}{ Disponibilidad } & \multicolumn{2}{|c|}{ AENOR } & \multicolumn{2}{|c|}{ Publicación } & \multirow[b]{2}{*}{ Observaciones } \\
\hline & & & Recepción & Idioma & UNE & DNA & \\
\hline $\begin{array}{l}\text { ENV 1994-1-1 } \\
\text { ENV 1994-1-2 } \\
\text { ENV 1994-2 }\end{array}$ & $\begin{array}{l}\text { Reglas generales y reglas para edificación } \\
\text { Proyecto de estructuras sometidas a fuego } \\
\text { Puentes }\end{array}$ & $\begin{array}{l}1992-10 \\
1994-10 \\
1997-10\left(^{*}\right)\end{array}$ & $\begin{array}{l}1992-11-04 \\
1994-11-11\end{array}$ & $\begin{array}{c}\text { E-F-D } \\
E\end{array}$ & $1995-06$ & $1995-06$ & Imprenta \\
\hline
\end{tabular}

EUROCODIGO 5: Proyecto de estructuras de madera

\begin{tabular}{|c|c|c|c|c|c|c|c|}
\hline \multirow[b]{2}{*}{ Parte } & \multirow[b]{2}{*}{ TItulo abreviado } & \multirow[b]{2}{*}{ Disponibulidad } & \multicolumn{2}{|c|}{ AENOR } & \multicolumn{2}{|c|}{ Publicación } & \multirow[b]{2}{*}{ Observaclones } \\
\hline & & & Recepción & Idioma & UNE & DNA & \\
\hline $\begin{array}{l}\text { ENV } 1995-1-1 \\
\text { ENV 1995-1-2 } \\
\text { ENV 1995-2 }\end{array}$ & $\begin{array}{l}\text { Reglas generales y reglas para edificación } \\
\text { Proyecto de estructuras sometidas a fuego } \\
\text { Puentes }\end{array}$ & $\begin{array}{l}1993-12 \\
1994-11 \\
1996-10(*)\end{array}$ & $\begin{array}{l}1993-12-29 \\
1994-12-12\end{array}$ & $\begin{array}{c}E-F-D \\
E\end{array}$ & & & $+A C$ \\
\hline
\end{tabular}

EUROCODIGO 6: Proyecto de estructuras de fábrica (albañilería)

\begin{tabular}{|c|c|c|c|c|c|c|c|}
\hline \multirow[b]{2}{*}{ Parte } & \multirow[b]{2}{*}{ Título abreviado } & \multirow[b]{2}{*}{ Disponibilidad } & \multicolumn{2}{|c|}{ AENOR } & \multicolumn{2}{|c|}{ Publicación } & \multirow[b]{2}{*}{ Observadione } \\
\hline & & & Recepción & Idioma & UNE & DNA & \\
\hline ENV 1996-1-1 & Reglas para fábrica armada y sin armar & $1995-06$ & $1995-06-26$ & E & & & \\
\hline ENV 1996-1-2 & Proyecto de estructuras sometidas a fuego & 1995-07 & $1995-07-21$ & E & & & \\
\hline ENV 1996-1-3 & Reglas detalladas para cargas laterales & $1996-04(*)$ & & & & & \\
\hline ENV 1996-2 & Diseño selección de materiales y ejecución de la fábrica. & $1996-10(*)$ & & & & & \\
\hline ENV 1996-3 & Reglas simplificadas & $1996-10(*)$ & & & & & \\
\hline
\end{tabular}

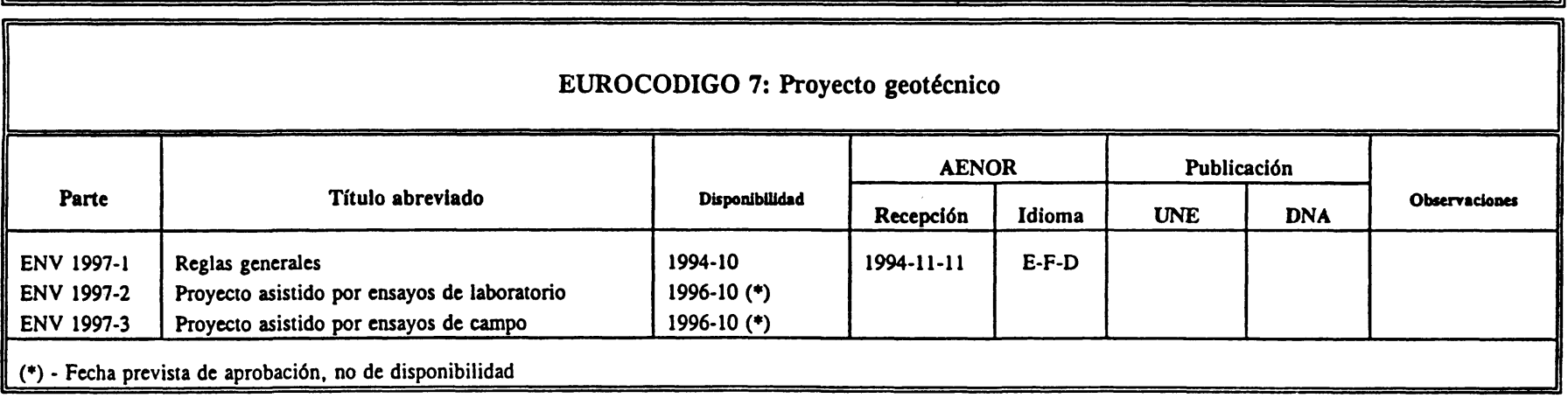

\begin{tabular}{|c|c|c|c|c|c|c|c|}
\hline \multicolumn{8}{|c|}{ EUROCODIGO 8: Proyecto para resistencia al sismo de las estructuras } \\
\hline \multirow[b]{2}{*}{ Parte } & \multirow[b]{2}{*}{ Título abreviado } & \multirow[b]{2}{*}{ Disponibilidad } & \multicolumn{2}{|c|}{ AENOR } & \multicolumn{2}{|c|}{ Publicación } & \multirow[b]{2}{*}{ Observaclones } \\
\hline & & & Recepción & Idioma & UNE & DNA & \\
\hline ENV 1998-1-1 & Acciones sismicas y requisitos generales para estructuras & 1994-10 & $1994-11-11$ & E-F & & & \\
\hline ENV 1998-1-2 & Reglas generales para edificación & 1994-10 & $1994-11-11$ & E-F & & & \\
\hline ENV 1998-1-3 & Reglas para materiales y elementos varios & 1995-02 & $1995-02-10$ & E & & & \\
\hline ENV 1998-1-4 & Refuerzo y reparación & 1996-01 & $1995-12-26$ & E & & & \\
\hline ENV 1998-2 & Puentes & 1994-12 & $1994-12-21$ & E & & & \\
\hline ENV 1998-3 & Torres, mástiles y chimeneas & $1996-03(*)$ & & & & & \\
\hline ENV $1998-4$ & Silos, tanques y conducciones & $1996-03(*)$ & & & & & \\
\hline ENV 1998-5 & Cimentaciones, estructuras de retención y aspectos geotécnicos & $1994-10$ & $1994-11-11$ & E & & & \\
\hline
\end{tabular}

\begin{tabular}{|c|c|c|c|c|c|c|c|}
\hline \multicolumn{8}{|c|}{ EUROCODIGO 9: Proyecto de estructuras de aleación de aluminio } \\
\hline \multirow[b]{2}{*}{ Partc } & \multirow[b]{2}{*}{ Título abreviado } & \multirow[b]{2}{*}{ Disponibilidad } & \multicolumn{2}{|c|}{ AENOR } & \multicolumn{2}{|c|}{ Publicación } & \multirow[b]{2}{*}{ Observacione: } \\
\hline & & & Recepción & Idioma & UNE & DNA & \\
\hline ENV $1999-1-1$ & Reglas generales y, reglas para edificación & $1997-10(*)$ & & & & & \\
\hline ENV 1999-1-2 & Proyecto de estructuras sometidas a fuego & $1997-04\left(^{*}\right)$ & & & & & \\
\hline ENV $1999-2$ & Reglas para estructuras sometidas a fatiga & $1997-04\left(^{*}\right)$ & & & & & \\
\hline
\end{tabular}

